\title{
Implementing Psychological Formulation into Complex Needs Homeless Hostels to develop a Psychologically Informed Environment.
}

Sophie Buckley, Anna Tickle \& Sarah McDonald.

Sophie conducted this research as part of her MSc Psychology in Clinical Practice degree at Nottingham Trent University. She spent six months on placement at Framework Housing Association working in hostels catering for homeless individuals with multiple complex needs. Sophie has since started as a trainee Clinical Psychologist on the Trent Doctorate in Clinical Psychology.

Anna is a Clinical Psychologist, working part time in clinical practice and part time on the Trent Doctorate in Clinical Psychology. She is currently on a two year secondment to Framework and Opportunity Nottingham to promote the development of psychologically-informed homelessness services. Anna is interested in the use of psychological theory and practice to promote change for individuals with complex needs and those supporting them. She conducts and supervises research to promote the development of practice-based evidence in a range of services.

Sarah is a lecturer in Psychology at Nottingham Trent University. She is a registered Clinical Psychologist and worked for a number of years in adult mental health in Nottingham and Nottinghamshire. Her main interests are in eating disorders, how new practices and policies are implemented in mental health services, and staff and service user experiences in mental health services. 


\section{$\underline{\text { ABSTRACT }}$}

This study explored the implementation of psychological team formulation in two single-gender hostels for homeless individuals experiencing multiple complex needs. Nine hostel staff took part in two semi-structured interviews, before and after attending up to eight formulation meetings. Thematic analysis identified that staff perceived team formulation to increase their understanding of service users, led to some developments within the team, and encouraged staff to take a different approach to their work, perceiving themselves and service users more positively; however, the usefulness of formulation was restricted by the systemic limitations. Results suggest team formulation has notable benefits for staff in hostels supporting individuals with multiple complex needs.

Key words: Hostels; Psychological formulation meetings; Qualitative

\section{INTRODUCTION}

Homelessness can range from episodic or temporary homelessness to long-term rough sleeping. The complex needs faced by individuals experiencing longer-term homelessness are grounded in community and neighbourhood contexts and social inequalities (O'Brien, O'Campo \& Brodsky, 1999; Shinn \& Toohey, 2003), which may contribute to unstable living conditions as well as: poorer outcomes in physical and mental health (Lippert \& Lee, 2015); difficulties in social and family relationships; reduced employment opportunities and increased risk of being both victims and perpetrators of crime. The association between homelessness and mental wellbeing is complex, but research suggests those experiencing long-term homelessness are at significantly higher risk of mental health difficulties (Lippert \& Lee, 2015). Substance use to cope with poor mental health is common (Homeless Link, 2014) but can lead to additional difficulties and interfere with active participation in support programmes (Opalach et al., 2015). These needs are compounded by the lack of accessibility to psychosocial services (Moore, Manias, \& Gerdtz, 2011).

Seager (2011) argues that perpetual rough sleeping signifies neglect of valued self or identity and paranoid levels of distrust together with rejection of dependency on others. However, critical thought should be given to such views, including the assumption that individuals are a homogenous group in terms of their self-identity and attitudes towards support. Such views tend to locate problems within individuals and downplay the impact of communities and social context in what might be described as 'context minimisation error' (Shinn \& Toohey, 2003). It is also important to recognise that individuals may have many strengths and skills, which tend to be overlooked by deficit-based approaches to identifying need, which may further contribute to social exclusion and reduced opportunities (Hammond \& Zimmerman, 2012).

Cumulative disadvantage theory offers an understanding of increased risk of mental health and other difficulties being the result of an accumulation of past and contemporaneous stressors, risk and trauma, which leads to persistently increased stress levels (Dannefer, 2003). Trauma is both 
a likely precedent for (Taylor \& Sharpe, 2008) and an outcome of homelessness (Goodman, Saxe, \& Harvey, 1991). 'Compound trauma' can result from several traumatic events occurring without the time, support, or capacity to process each of them or to recover (Cockersell, 2018).Social disafilliation and learned helplessness are often seen in individuals experiencing homelessness and are also symptoms of post-traumatic stress disorder (Goodman et al., 1991). A socioecological (Bronfenbrenner, 1979) understanding of trauma recognises the role of different levels of the system around the individual to both contribute towards trauma and also recovery, but there is also a need to understand that chronic stress and adversity on organisations supporting individuals who have experienced trauma can impact service delivery (Bloom, 2010). The need for homelessness services to adopt trauma-informed care is evident (Hopper, Bassuk \& Olivet, 2009).

Hostels are common temporary accommodation provision in the UK, including those offering higher support for those with 'multiple complex needs', which usually refers to needs relating to homelessness, substance misuse, offending and mental health. While there is a growing movement of 'Housing First' provision of independent stable housing (see hfe.homeless.org.uk), this is in relatively early stages of development, meaning hostels are likely to continue for some time and may also continue to be the main provision for individuals who have complex needs but have not been rough sleeping. Current commissioning and provision typically consist of shortterm, fragmented support and focus primarily on provision of physical shelter rather than the possible psychological shelter the relationships developed within a service can provide (Seager, 2011). The 'New Public Management' paradigm of resourcing social interventions focuses on markets, managers, and measurement of 'outcomes', limiting responsiveness to 'the reality of our complex world and the knottiness of people's lives' (Davidson Knight, Low, Brossard \& Wilson, 2017, p.5) or the importance of relationships.

The UK government austerity agenda has further created a context of increased pressure, limited resources and relationships often characterised by conditionality and disconnection (Watson, Nolte, \& Brown, 2018). Such conditionality, together with a high prevalence of compound trauma amongst residents may contribute to distrust of services, disengagement, and destructive behaviours; this may in turn lead to serious incidents, abandonment of beds or evictions and staff feeling ill-equipped to support people (Homeless Link, 2017). Most frontline homelessness staff have no clinical training yet support those most in need of psychologically informed help but least able to access psychological services (Keats, Maguire, Johnson \& Cockersell, 2012). Consequent low morale, burnout and high turnover in the workforce (Olivet, McGraw, Grandin, \& Bassuk, 2010) can further limit the potential for service users to benefit from stable relationships within services. 
In response, many services are moving towards working within the framework provided by Psychologically Informed Environments (PIE) (PIElink, 2019), which has five key elements: psychological awareness; staff training and support; learning and enquiry; spaces of opportunity; and the three R's (rules, roles, and responsiveness). Relationships are understood to underpin all elements. There is emerging evidence for the benefits of PIE approaches within hostels, including reduced evictions and increased engagement between staff and service users (Williamson, 2018), and staff feeling better equipped, less burnout and reduced turnover (Homeless Link, 2018). Staff also report PIE implementation increases their understanding of complex trauma and ability and confidence to engage service users creatively (Templeton, 2018). However, there are few published examples or evaluations of mechanisms through which PIE can be implemented.

A method of working common in clinical psychology services that can support PIE approaches is the use of team psychological formulation meetings. Psychological formulation has been defined as a 'hypothesis about the causes, precipitants, and maintaining influences of a person's psychological, interpersonal and behavioural problems' (Eells, 2007, p.4). The essential features of a thorough formulation draw upon psychological theories and models to: summarise the service user's core problems; suggest how difficulties relate to one another; explain the development and maintenance of the difficulties; and indicate a plan of intervention (Johnstone \& Dallos, 2014). Formulations should include the individual's strengths and be person- rather than problem-specific, culturally sensitive, and aware of organisational/systemic factors (Division of Clinical Psychology, 2011).

Team formulation (TF) refers to approaches through which clinical psychologists support teams to incorporate psychological thinking into support for service users using an accessible, collaborative, and reflective approach (Geach, Moghaddam, \& De Boos, 2018). In this paper, TF refers to a collaborative discussion in the team, facilitated by a clinical psychologist and structured around specific psychological formulation models. The aims of TF map directly onto the principles of PIE through raising staff members' psychological awareness; being a form of staff support and encouraging reflectiveness; encouraging learning and enquiry about individual service users; considering opportunities and roles for the service user; and discussing the way in which service rules are applied and how the team can tailor their responsiveness according to the specific needs of the individual.

Although there are varied definitions and implementation of $\mathrm{TF}$, together with limitations in methods of evaluation, a meta-analysis found that staff report TF leads to improved psychological understanding and attitudes towards service users (Geach et al., 2018). This includes staff feeling increased confidence in their work, perceiving service users more positively and optimistically (Berry et al., 2009), increased empathy towards service users, and increased consistency within 
the team (Whitton et al., 2016). However, such results are limited to health and forensic services in the UK, limiting transferability to other services beyond these contexts, including homelessness services. Any service using TF needs to adapt the specific implementation according to factors such as the time somebody is within the service, the level and type of information that might be known about them, and the specific remit of the staff and service. In hostel settings, support primarily focuses on resettlement into longer-term accommodation and information about developmental histories may be very limited.

Given the apparent fit between TF and PIE, TF was implemented by the second author in two single-gender hostels for individuals with multiple complex needs, which were seeking to develop their practice in line with the PIE approach. Due to service constraints the meetings lasted one hour and were attended by whoever was on shift at the time. The first author assisted in the TF meetings, examining the information available on the service user being explored, coming up with preliminary ideas and assisting the clinical psychologist in deciding which formulation to use.

The meetings were predominantly structured around cognitive-behavioural developmental formulations (Beck, 1970) to encourage staff to think about the service user's inner world and consider how thoughts and feelings might influence behaviour (Fennell, 1998); attachment theory was also incorporated to consider the individual's relational style and how they express their needs through their behaviour (Connolly, 2018) and how staff might tailor their approach. The meetings discussed the service user's history, including critical incidents; views of self, others and the world; rules for living; and patterns of behaviour. There is a risk that such models could be seen as encouraging 'context minimisation error' (Shinn \& Toohey, 2003). However, in line with the behavioural principle within CBT, emphasis was placed on the environments in which the individual developed and currently lived, including the hostel and wider community, accounting for socio-ecological factors influencing them. In line with the cognitive principle, consideration was given to the appraisals the individual expressed in relation to themselves, others and the world, which likely influence their responses to their environments. Given the context, 'interventions' following from the formulation often related to the team approach to building a relationship with the individual, as well as wider ideas for supporting the individual to build on strengths and to navigate, manage, or challenge their socio-ecological context as appropriate. The facilitator would guide team members through the structured discussion, with space for everybody present to contribute their views.

Professionals working with the service user from various services were invited to the meetings including probation, social workers, and substance misuse recovery workers. Each meeting was checked against the Division of Clinical Psychology's (2011) good practice guidelines for formulation, and if any criteria was not met this was discussed with the clinical psychologist 
following the meeting. This study aimed to use a qualitative approach to inductively answer the question: What are team members' views of the implementation of TF?

\section{METHODS}

Design

A qualitative, pre- post-design was used to explore team members' views before and after the implementation of formulation meetings in each service.

Hostels

Participating teams were from two single gender 'complex needs' hostels (one male, one female) within a homelessness housing agency in a city in the East Midlands, UK. Both hostels have 15 beds and are staffed 24 hours with a minimum of two members of staff. Each team comprises a manager and deputy, two support planners, around four support workers and night staff. Referrals usually come from the local Housing Aid department or other services within the same agency. The hostels take individuals with historical or (more usually) current substance misuse, offending behaviour, and / or mental health problems. The services are contracted to provide a stay of up to six months, with the intention that individuals move on to lower support (unstaffed) shared or independent housing. While many do so, not all are able to move on within six months, for reasons that include a lack of affordable available options or higher support needs that require a specialist placement to be sought. Residents sign tenancy agreements and are expected to engage in regular support sessions with staff. Rules are kept to a minimum and support provided to residents to maintain their tenancies except in clear cases of illegal behaviours that put others at direct risk (e.g. drug dealing, assaults), which can lead to eviction.

Participants

Nine permanent day staff were recruited from one hostel for men (staff participant $n=4$ ) and one for women (staff participant $n=5$ ). Participants included managers, support planners, and support workers, who all work with service users to support them to move on to suitable accommodation and access specialist services. All participants took part in both interviews. All participants were given pseudonyms to ensure anonymity. Individual participant information is available in Table 1. Averages across participants are as follows: years in current role $(m=3.78$ $s d=2.32)$; time in similar roles $(m=14.78, s d=7.28)$; and formulation meetings attended of the eight included in the study ( $m=4.56, s d=0.88)$.

Procedure 
This study received ethical approval from Nottingham Trent University. All permanent day staff in the hostels were given a participant information sheet and interviews were arranged with staff who gave written consent. Interview one took place before participants had attended any $\mathrm{TF}$ meetings. A semi-structured interview schedule was developed to explore staff members' current understanding of service users and their views in anticipation of the meetings. Interview two was arranged following eight weekly TF meetings. A semi-structured interview schedule was developed to explore participants' perceptions of the meetings. Interviews lasted between 25 and 55 minutes and were audio-recorded and transcribed verbatim.

\section{Data Analysis}

A critical realist (CR) epistemological stance was taken towards the data. CR recognises the fallibility of knowledge, so 'responsible rationality' is practiced in research (Manicas, 2009), and understands that the complexity of the world implies our knowledge is limited and influenced by various social structures and pressures that cannot necessarily be controlled (Benton \& Craib, 2001). CR recognises the conditional nature of results (Bhaskar, 1979). We used an inductive approach to coding data, due to the lack of research exploring TF in housing homelessness contexts.

Data was analysed using thematic analysis, guided by Braun and Clarke's (2006) approach. This involves : a) verbatim transcription followed by familiarisation through reading and re-reading of data and noting of initial ideas; b) inductive coding of both transcripts from one participant, using participants' language to retain as much meaning as possible. Following coding of the entire dataset, any codes that were not related to the research question were discarded; c) Codes from both interviews were grouped into initial themes, separating codes from interview one and two. These codes and initial themes were then re-examined in relation to the research question and the whole dataset to ensure that the analysis was answering the question and to identify how many participants discussed each theme and whether the theme was prevalent in both interviews. No arbitrary minimum number of participants was set to determine what constituted a theme, but all themes were constructed from codes that were prevalent across multiple participants and that indicated a pattern in their experience of the meetings. Initial themes were then explored in a thematic map and refined, grouped and named accordingly. This stage was done twice, once solely by the first author and again with supervision from the second author to further refine the themes and subthemes to clarify the results.

\section{Reflexivity}

The first author began the research with little previous contact with participants. As the research progressed the author spent more time in the hostels building rapport with staff; this increased 
relationship may have led to participants being more forthcoming in the second interviews, as seen by the increased codes developed from the second interviews. The authors are aware that their personal and professional views on homelessness and a desire to support those marginalised by society may have led to an unconscious desire to develop positive results. Whilst all efforts were taken to ensure the interview questions were open and the delivery of such questions was unbiased, there is some likelihood that questions were framed to gather results deemed useful and appropriate. However, continual discussion and reflexive supervision, as well as supervision by the third author who was external to the services, assisted in managing bias throughout.

\section{$\underline{\text { RESULTS }}$}

Four main themes were developed: Increasing psychological awareness and understanding of service users; Stopping, thinking and doing something different; A constraining context; and Recognising and reinforcing good practice. Each theme is explored below using direct quotes from participants.

\section{Increasing psychological awareness and understanding of service users}

Prior to the meetings beginning, participants most hoped to gain:

“... more of an insight I think into some of the reasons why some of the women ... behave in the ways that they do ... It's easier to find ways of working with somebody if you've got an understanding of some of the more bizarre pieces of behaviour."

Kate, Interview 1, Lines 72-73.

All perceived an increased understanding of service users following the TF meetings. This included a better understanding of the service users' inner world, patterns of behaviour, as well as increased awareness of how staff behaviour may be perceived by service users. While participants knew information about service users, they described the TF meetings as the forum in which this information could be joined "just like a dot-to-dot, I can put the line over there and over there and I can get it now and it makes sense" (Amy, Interview 2, Lines 265-266). Across the team the meetings were a way to "start putting the jigsaw together that little bit more" Yasmin, Interview 2, Lines 78-79.

The meetings helped to increase staff members' empathy towards the people they work with. Anne epitomised this shift, stating: 
"One of the worries I do have is ... that my empathy levels are dwindling ... it (formulation meetings) makes you look at them more as a person ... to think about the things that people have gone through in their personal life and their childhood ... it helps me that way." (Interview 2, Lines 13-16).

Participants reported a better understanding of how trauma is likely to influence service users' perceptions of others and of patterns of behaviour they observed in service users. Such recognition often focused on the relationship between the service user and services, e.g. 'Particularly people who they see as in positions of authority or people who are in effect in positions of more power than they are." Kate, Interview 2, Lines 34-36. Such recognition was new even to staff members who were very experienced in such settings, e.g.

"I hadn't thought about that before that it was a pattern that they (service users) just expected (to be evicted) ... it's almost as if they've got less control than they would like about how they start behaving in that period you know and it's about being more aware of that and ... giving them ... a lot more encouragement before that period that they're doing really well."

Amy, Interview 2, Lines 93-100.

Overall, it appears that using a developmental psychological framework to bring together information about an individual's past and present gave rise to a more coherent understanding of the individual, which in turn helped to make more sense of service users' behaviour. In this sense, the meetings had a systemic impact within the service, changing staff perceptions of those they were supporting and the type of support that might be needed. This supports the use of TF as an effective tool in homelessness services integrating a PIE approach.

\section{Stopping, thinking, and doing something different}

There was evidence that the meetings influenced staff members' approach to their work. Only Eve had mentioned reflection as something she hoped to gain from the meetings prior to them beginning:

"Hopefully this will be better to help us understand our emotions and our feelings and what we do with all of that." Interview 1, Lines 166-167.

In the second interviews, half of participants reported being more reflective as an outcome of the meetings, but almost everyone discussed how they were likely to stop, think and change their approach in working with a service user following the meetings.

"I think it's made me ... want to ... double take for one. So just to say right okay maybe this isn't working because of this ... so if I try something totally different then maybe I'll get a 
better result."

Nathan, Interview 2, Lines 30-32.

There was acknowledgement by some participants of the impact of the meetings and increased empathy on their approach to interacting with residents, which perhaps also hinted at their feelings about work: "I've been just trying to stay calmer so I can focus more of what will help them rather than getting stressed or being shouty.” (Anne, Interview 2, Lines 21-22).

Beyond interactions, Matthew hoped to take the information from the meetings into developing support plans, acknowledging the importance of use of language in doing so:

“(Want to be able to) take that ... formulation and bend it into that person's support plan in a way that allows us to work with them in a more informed way without the risk of triggering the people looking at it and saying well that looks frightening ... I try to be really careful about the way I describe things."

Matthew, Interview 2, Lines 150-153.

Participants noted various ways in which TF enabled them to feel more confident and encouraged them to change their approach to work, being markedly more: reflective, creative, flexible, and person-centred in their approach.

Prior to the implementation of team formulation, participants in both services expressed that there was not a consistent team approach towards service users. Following the meetings, some perceived this had changed: e.g.

"It's probably made us look more at working the same way with a person. That used to be quite frustrating that you would work completely different to another worker and then the service user would end up feeling ... confused ... But now it feels a bit more uniformed overall."

Anne, Interview 2, Lines 39-42.

There were still some reports of inconsistency, which seemed to relate to the openness of staff to the new approach, e.g.

"I still think it's mixed ... I think some people get it some people don't get it, some people like it some people don't ... I think the challenge is ... either everybody embraces it, or we don't really embrace it and then how does that work within the team environment?" Nathan, Interview 2, Lines 68-70.

There might still be some way to go to achieve consistency in approach within the teams, which may be expected given that this was a two month pilot and that participants did not attend all 
eight meetings (due to shift patterns). It is to be expected that it may take longer to work towards a culture of consistency across the teams, but there was other evidence of movement towards this as a result of the meetings

In contrast to the feelings of hopelessness previously identified, some spoke about how the meetings have in fact "made us feel a little bit more empowered" (Kate, Interview 2, Line 67). Although the meetings focused on individual service users, a few people hinted that the learning from the meetings could be generalised, e.g.

"I think we've learnt an awful lot about the service users and ... we can relate a lot of what we've discussed (in the meetings) to service users in the future."

Eve, Interview 2, Lines 117-119.

This in turn gave rise to:

"Looking at the service as a whole as well: how they live, here how we can improve that, what adjustments we can make whether it's large or small." Eve, Interview 2, Lines 24-25.Finally, staff reported that the meetings encouraged collaboration with external services, which suggests better working with wider agencies and systems is both possible and valuable.

"I like the fact it comes from different views and different services and people involved and we put it all together ... I think you can get another understanding of somebody."

Yasmin, Interview 2, Lines 164-165.

Fundamentally, this theme evidences that staff not only thought they had a better understanding of service users, but also that they were consequently beginning to change their practice, both as individuals and as a team. It also indicates the importance of the whole team being open to the meetings and the change in practice that they might encourage.

\section{A constraining context}

Multiple participants questioned the usefulness of the meetings in relation to two subthemes: Sharpened awareness of systemic constraints; and Risk of consequent staff hopelessness.

\subsection{Sharpened awareness of systemic constraints}

Staff reported systemic limitations to be the biggest barrier to the success of TF, including a lack of resources and the time constraints to move individuals onto housing in six months or less. The meetings highlighted the constraints of services in being able to meet service users' needs, e.g. 
"What I found really frustrating ... not the meetings themselves, but that we don't have the time to work with the people in the way we want to ... it made it very clear really how little we can hope to achieve in the time that we've got to work with people."

Kate, Interview 2, Lines 21-23.

The acute awareness of limitations of the system extended to a sense of threat to the service borne out of New Public Management commissioning systems:

"I know that's not what I personally would want but the tender ... is six months ... we have to be realistic ... (if) we're not hitting the tender targets ... we're not going to have a service and that's bad for the (service users) and the staff.... as much as it would be nice to focus on the longer term ... realistically ... we need to be looking at them more shorter-term goals.” Natalie, Interview 2, Lines 131-134.

This raises a wider question of whether services can meet individuals' needs within existing commissioning systems, which is beyond the scope of the present research. Within existing hostel services for people with multiple complex needs, this subtheme suggests potential perceived challenges to the utility of team formulation and the need for recommendations produced within the meetings to focus on more immediate needs and goals rather than longerterm interventions.

\subsection{Risk of increasing staff hopelessness}

Recognition of systemic pressures lead staff to feelings of "despondency" (Emily, Interview 1, Lines 99 - 101), hopelessness and powerlessness, as they were unable to see how they can successfully build trusting, meaningful relationships with service users as well as moving them into suitable accommodation. The meetings exacerbated such feelings:

"It's made me feel ... more powerless because we're not in a position to change anything ... I'm not saying that's all about the meetings, because that powerlessness was there anyway, but I think they've highlighted that for me."

Kate, Interview 2, Lines 40-44.

Despite the strong feelings raised for participants about the contexts in which they work, which could be assumed to increase risk of low morale, there were some contradictory findings. Participants on the one hand talked about the meetings as ineffective, and on the other reported various positive outcomes for individual staff members, the team and the service. Despite questioning the effectiveness, the meetings also became a tool to be called upon after the initial eight weekly meetings: 
"I think generally they've been good I just don't know how effective they've been... that being said I asked for one about (service user) so in some part of my brain I must think they work and that I appreciate them"

Matthew, Interview 2, Lines 127-128.

Overall, this theme raises important implications for the adaptation of team formulation within complex needs hostels due to the potential for them to increase attendees' difficult feelings in relation to their work. A facilitator should prepare staff for this possibility and also support them to work through and appropriately respond to feelings such as powerlessness, whether their own or on behalf of the individuals they are supporting. Any interventions developed from the formulation need to strike a balance between pushing the boundaries of systems to achieve the best possible outcomes for individuals versus promoting unfeasible outcomes, which may serve to increase a sense of powerlessness or hopelessness.

\section{Recognising and reinforcing good practice}

Some participants were surprised that the meetings offered a chance to receive positive feedback and recognise good practice that existed.

"You don't really get feedback for positive things very often; people are more likely to come ... when you've done something crap. So that was quite nice, I was just surprised sitting there talking that we are already doing a lot of the things, not that we don't need to get better at them, but a lot of the things we're already doing."

Natalie, Interview 2, Lines 156-158.

It is possible that some of the feelings of powerlessness experienced by staff and the lack of recognition of good and effective practice prior to the meetings are evidence of the impact of organisations operating in a context of chronic stress, both related to pressure of producing outcomes and also providing support to people who have experienced significant trauma. It may be that wider organisational contexts that encourage a focus on deficits and problems may encourage them to focus on their own deficits also.

This positive feedback may act as a reinforcer for staff, encouraging continuing good work and acting as a positive incentive to attend and engage in TF meetings. Furthermore, this finding supports the idea that TF meetings fit well within a PIE approach, which emphasises the need for staff support and learning and enquiry, including reflective practice. The meetings encouraged staff to reflect on and recognise their good practice, as well as suggest new ways of working. This perhaps counteracts some of the potential effects of recognising the constraints of the system, by highlighting to team members their existing resources and potential to do things 
differently even within those constraints. The limitations of short-term hostel provision and the pressure staff operate under in terms of demonstrating 'resettlement' of people facing multiple needs must not be underestimated. The results indicate that it is this context that contributes to staff experiencing low morale as much as any of the behaviours of individuals they support. However, overall the results show that using psychological formulation meetings can support staff to develop reflection on their practice and, in doing so, lead to changes in staff behaviour at an individual and team level.

\section{DISCUSSION}

The present study explored the implementation of team formulation (TF) in two single-gender hostels for homeless individuals with multiple complex needs as part of developing a psychologically informed approach. Two themes that emerged in this study appear to corroborate previous literature from other service settings (Geach et al., 2018), finding that TF led to staff having a greater understanding of service users, being more confident, flexible, and creative in their approach, having more empathy towards service users, and some evidence of development within the team. These findings can be seen to support the various domains of PIE (PIElink, 2019), but with particular focus on three: developing psychological awareness of individuals services users and offering staff support to recognise good practice and areas for development through a process of learning and enquiry.

Staff were surprised that the meetings offered a space to receive positive feedback for their work; such feedback has been shown to increase work performance and positive emotions towards work (Choi et al., 2018). Additionally, increased collaboration with external agencies supports PIE spaces of opportunity; the meetings appear to offer a good starting point for building those relationships and working collaboratively to support service users promoting new external pathways and roles for both staff and service users. The meetings gave rise to thinking about changes that could be made in the service to benefit residents. Such broader learning was not found in previous TF studies but suggest that TF has various benefits that extend beyond the individual being discussed within the meeting. There was also evidence that participants were more informed and aware of the impact of trauma and conscious of power in relation to their roles and service user perceptions, suggesting the meetings offer a way of addressing some of the principles of trauma informed care (Hopper et al., 2009).

These outcomes, however, were limited by the constraining context in which staff operate, something not yet explored in the TF literature. This may be due to the contextual differences in which the research was undertaken, or because the TF literature is still in its early stages, and there may be some reporter bias towards focusing on the positive outcomes to bolster TF as a 
useful and effective mechanism, ignoring limitations that are not easily changed. The finding suggests that it might be helpful to pave the way for formulation meetings within multiple complex needs homelessness services by setting realistic expectations with attendees, including the potential for them to experience emotional reactions that might be associated with burnout, as found in other studies of workers in the homeless sector (Oliver et al., 2010). Consideration must be given to the impact of the broader communities in which services operate (Shinn \& Toohey, 2003) and the possibility for services to become 'trauma organised' (Bloom, 2010). These contexts are likely to influence staff views about what is possible, and how able they are to take a strengths-focused perspective (Hammond \& Zimmerman, 2012) versus focusing on deficits of individual service users, themselves, and wider systems.

There are some moves towards recognising the contextual constraints of New Public Management (Davidson Knight et al., 2017) and moves to address the limitations of hostels governed by a housing system operating in this paradigm, such as Housing First schemes. However, while hostels continue to operate, this study offers evidence of one mechanism for supporting staff to develop psychologically informed practice and develop day-to-day practice to be more tailored towards individual service users even within the perceived constraints of the system. While the formulations used individual developmental psychological theory as their foundation, there is evidence that this led to change in staff perceptions, awareness of service user needs and behaviour towards them, thus changing the microsystem in which residents are living. Perhaps in using TF there needs to be explicit acknowledgement limitations of wider systemic levels and power to effect immediate change in them; it could be hypothesised that this may reduce feelings of hopelessness in staff, and provide clarification of what could actually be achieved within service-specific constraints. This should be done alongside broader service work to promote greater flexibility in commissioning and service delivery that might better meet the challenges of complexity (Davidson Knight et al., 2017), as well as other interventions at wider systems levels targeting issues relating to both causes of and responses to homelessness, mental health, substance use and offending.

The present study offers some support for previous findings that TF led to improved consistency within staff teams (Geach et al., 2018), although results were mixed. This discrepancy in findings may reflect that previous research took place in a setting within which TF was an already established practice (Whitton et al., 2016), compared to the present study looking at the implementation of TF over eight weeks. It could be hypothesised that staff would be more likely to report increased consistency once TF was a regular, established practice. Truly embedding the principles of PIE into team and service culture requires an openness towards changing practice. The participants of this study generally had such openness, and this may have influenced the 
findings. Other services considering implementation of TF to promote psychological thinking should address the openness of individual staff members to this.

One limitation of the current research stems from conducting interviews before and after the formulation meetings, whilst this was done to offer the author a point of context prior to TF being implemented, alongside the chance the gather any hopes staff members had about the meetings. There is the possibility that in analysing interview one, followed by interview two, the author would subconsciously be looking for themes throughout interview two that fit the narrative of the first interview. The author actively tried to mitigate this through ongoing reflexivity and by coding the entirety of the dataset even if it did not appear to be related to the research question; this then offered a large amount of inductive, participant-led codes which were then examined to identify themes. As the focus of the research was primarily the perceptions of staff about the meetings, the themes were primarily developed based on the interviews carried out after they had attended the meetings, the first interview offering the author some context and a point of comparison.

Another limitation of the present study is that no feedback was gathered from service users to triangulate participants' reports of changing practice. It could be argued that future research would benefit from gathering direct service user feedback to identify if TF leads to any noticeable differences for the service users. It is acknowledged this would be challenging to achieve given the difficulties that bring individuals to the service and the power dynamics between staff and residents.

During the research, there were several vacant posts within both the hostels; this likely impacted staff's perception of limited resources and may offer some explanation as to the prevalence of limitations identified in the results and the inconsistencies in reporting consistency within the team. Only permanent day staff were recruited for this study as they are a more regular presence in the service, however, relief staff also took part in the TF meetings. As some participants discussed the transferrable skills of the TF meetings, it could be hypothesised that they would be useful for relief staff as well as permanent staff and it would be useful to explore the outcomes for relief staff and any differences between them and permanent staff.

A final suggestion for future research comes from the participants' reports of feelings of hopelessness and powerlessness within their work, highlighted by the TF meetings. As previously mentioned, this juxtaposition staff appeared to feel between seeing TF as a useful tool with various positive outcomes, versus the systemic and organisational contexts that limit any such outcomes or relationship building (Watson et al., 2018). It may be helpful for research to establish the prevalence and impact of such negative feelings, and possible interventions to address such 
feelings amongst staff working in a housing agency with individuals experiences multiple complex needs, alongside broader research to evidence innovative practice that seeks to address these limitations.

In conclusion, the current study suggests that $\mathrm{TF}$ appears to be a promising addition to homelessness services for people experiencing multiple complex needs. Staff may require support to anticipate and respond to feelings of powerlessness within the wider system that meetings may elicit. However, in spite of these feelings TF clearly supports the development of a psychologically informed environment as reported by staff and offers a space of opportunity for staff to develop their psychological understanding, reflect, and collaborate within and across services.

\section{Declaration of Interest}

The authors report no conflicts of interest.

\section{REFERENCES}

Beck, A. T. (1970). Cognitive therapy: Nature and relation to behavior therapy. Behavior Therapy, 1(2), 184-200. http://dx.doi.org/10.1016/S0005-7894(70)80030-2

Benton, T., \& Craib, I. (2011). Philosophy of science: The foundations of philosophical thought, London: Palgrave Macmillan.

Berry, K., Haddock, G., Kellett, S., Roberts, C., Drake, R., \& Barrowclough, C. (2016). Feasibility of a ward-based psychological intervention to improve staff and patient relationships in psychiatric rehabilitation settings. The British Journal of Clinical Psychology, 55(3), 236-52. https://doi.org/10.1111/bjc.12082

Bhaskar, R. (1979). The possibility of naturalism: A philosophical critique of the contemporary human sciences. Atlantic Highlands, NJ: Humanities Press. 
Bloom, S. (2010). Trauma-organised systems and parallel process. In: N. Tehrani (Ed.). Managing trauma in the workplace. Supporting workers and organisations. London: Routledge, pp. 139 - 152.

Braun, V., \& Clarke, V. (2006). Using thematic analysis in psychology. Qualitative Research in Psychology, 3(2), 77-101. http://dx.doi.org/10.1191/1478088706qp063oa

Bronfenbrenner, U. (1979). The ecology of human development. Cambridge, Massachusetts: Harvard University Press.

Choi, E., Johnson, D., Moon, K., \& Oah, S. (2018). Effects of Positive and Negative Feedback Sequence on Work Performance and Emotional Responses. Journal of

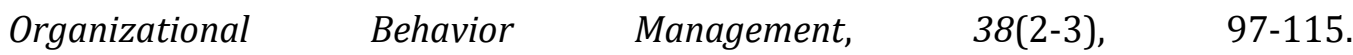
https://psycnet.apa.org/doi/10.1080/01608061.2017.1423151

Cockersell, P. (2018). Compound Trauma and Complex Needs. In P, Cockersell (Ed), Social Exclusion, Compound Trauma and Recovery: Applying Psychology, Psychotherapy and PIE to Homelessness and Complex Needs (pp. 26-36). London and Philadelphia: Jessica Kingsley Publishers.

Connolly, J. (2018). A Pre-Treatment Therapy Approach for Single Homeless People: The Co-Construction of Recovery/Discovery. In P, Cockersell (Ed), Social Exclusion, Compound Trauma and Recovery: Applying Psychology, Psychotherapy and PIE to Homelessness and Complex Needs (pp. 109-133). London and Philadelphia: Jessica Kingsley Publishers.

Dannefer, D. (2003). Cumulative advantage/disadvantage and the life course: Crossfertilizing age and social science theory. The Journals of Gerontology Series B: Psychological Sciences and Social Sciences, 58(6), S327-S337. https://doi.org/10.1093/geronb/58.6.S327

Davidson Knight, A., Lowe, T., Brossard, M., \& Wilson, J. (2017). A whole new world: Funding and commissioning in complexity. London: Collaborate for Social Change.

Division of Clinical Psychology. (2011). Good Practice Guidelines on the use of psychological formulation. Leicester: British Psychological Society.

Eells, T.D. (Ed.) (2007). Handbook of psychotherapy case formulation. London, UK: Guildford Press. 
Fennell, M. J. (1998). Cognitive therapy in the treatment of low self-esteem. Advances in Psychiatric Treatment, 4(5), 296-304. http://apt.rcpsych.org/content/4/5/296.citation\#BIBL

Geach, N., Moghaddam, N.G., \& De Boos, D. (2017). A systematic review of team formulation in clinical psychology practice: Definition, implementation and outcomes. Psychology and Psychotherapy: Theory, Research and Practice, 91, 186 215. https://doi.org/10.1111/papt.12155

Goodman, L., Saxe, L., \& Harvey, M. (1991). Homelessness as psychological trauma: Broadening perspectives. American Psychologist, 46(11), 1219-1225. https://psycnet.apa.org/doi/10.1037/0003-066X.46.11.1219

Hammond, W. \& Zimmerman, R. (2012). A strengths-based perspective. Available at: https://www.esd.ca/Programs/Resiliency/Documents/RSL STRENGTH BASED PERSP ECTIVE.pdf (accessed 20.02.20).

Homeless Link. (2014). The Unhealthy State of Homelessness: Health Audit Results 2014. London: Homeless Link. Available at: https://www.homeless.org.uk/sites/default/files/siteattachments/The\%20unhealthy\%20state\%20of\%20homelessness\%20FINAL.pdf

Homeless Link. (2017). An introduction to Psychologically Informed Environments and Trauma Informed Care. London: Homeless Link. Available at: https://www.homeless.org.uk/sites/default/files/siteattachments/TIC\%20PIE\%20briefing\%20March\%202017_0.pdf

Homeless Link. (2018). The Future Hostel. The role of hostels in helping to end homelessness. London: Homeless Link. Available at: https://www.homeless.org.uk/sites/default/files/siteattachments/The\%20Future\%20Hostel_June\%202018.pdf

Hopper, E.K., Bassuk, E.L., \& Olivet, J. (2009). Shelter from the storm: Trauma-informed care in homelessness service settings. The Open Health Services and Policy Journal, $2,131-151$.

Johnstone, L. \& Dallos, R. (2014). Formulation in psychology and psychotherapy: making sense of people's problems (2nd ed.). East Sussex, England; New York: Routledge.

Keats, H., Maguire, N., Johnson, R., \& Cockersell, P. (2012). Psychologically informed services for homeless people. Good practice guide. Available at: 
https://eprints.soton.ac.uk/340022/1/Good\%2520practice\%2520guide\%2520\%2520\%2520Psychologically\%2520informed\%2520services\%2520for\%2520homeless \%2520people\%2520.pdf

Lippert, A., \& Lee, B. (2015). Stress, Coping, and Mental Health Differences among Homeless People. Sociological Inquiry, 85(3), 343-374. https://doi.org/10.1111/soin.12080

Manicas, P. T. (2009). Realist metatheory and qualitative methods. Available at: http://citeseerx.ist.psu.edu/viewdoc/download?doi=10.1.1.733.9860\&rep=rep1\&type $=$ pdf

Moore, G., Manias, E., \& Gerdtz, M. F. (2011). Complex health service needs for people who are homeless. Australian Health Review, 35(4), 480-485. https://doi.org/10.1071/AH10967

O’Brien Caughy, M., O’Campo, P., \& Brodsky, A.E. (1999). Neighborhoods, families and children: implications for policy and practice. Journal of Community Psychology, 27(5), 615 - 633. https://doi.org/10.1002/(SICI)15206629(199909)27:5\%3C615::AID-JCOP8\%3E3.0.C0;2-F

Oliver, J., McGraw, S., Grandin, M. \& Bassuk, E. (2010). Staffing challenges and strategies for organizations serving individuals who have experienced chronic homelessness. The Journal of Behavioral Health Services \& Research, 37(2), 226 238. https://doi.org/10.1007/s11414-009-9201-3

Opalach, C., Romaszko, J., Jaracz, M., Kuchta, R., Borkowska, A., \& Buciński, A. (2016). Coping styles and alcohol dependence among homeless people. PloS One, 11(9), e0162381. https://doi.org/10.1371/journal.pone.0162381

PIElink (2019). PIEs 1 \& 2.0: The Revised Account. Retrieved from http://pielink.net/pies-2$0 /$

Seager, M. (2011). Homelessness is more than houselessness: A psychologically-minded approach to inclusion and rough sleeping. Mental Health and Social Inclusion, 15(4), 183-189. https://doi.org/10.1108/20428301111186822

Shinn, M. \& Toohey, M. (2003). Community contexts of human welfare. Annual Review of Psychology, 54, 427 - 459.

https://doi.org10.1146/annurev.psych.54.101601.145052. 
Taylor, K., \& Sharpe, L. (2008). Trauma and Post-Traumatic Stress Disorder Among Homeless Adults in Sydney. Australian and New Zealand Journal of Psychiatry, 42(3), 206-213. https://doi.org/10.1080/00048670701827218

Templeton, J. (2018). St. Basil's PIE - A whole organisational approach Psychologically Informed Environments. Presentation given at the St. Basil Psychologically Informed Environments Symposium, 26th November 2018, Birmingham.

Watson, C., Nolte, L., \& Brown, R. (2018). Building connection against the odds: project workers relationships with people experiencing homelessness. Housing, Care and Support, 22(2), 129 - 140. https://doi.org/10.1108/HCS-10-2018-0030.

Whitton, C., Small, M., Lyon, H., Barker, L., \& Akiboh, M. (2016). The impact of case formulation meetings for teams. Advances in Mental Health and Intellectual Disabilities, 10(2), 145-157. https://psycnet.apa.org/doi/10.1108/AMHID-092015-0044

Williamson, E. (2018). Psychologically Informed Environments. Presentation given at the Greater Manchester Mental Health and Homelessness Conference, 3rd October 2018, Manchester. Slides available at: https://www.gmmh.nhs.uk/news/clinicians-from-across-the-uk-join-forces-totackle-mental-health-and-homelessness-2369 